\title{
Environmental Factors Associated With Type 1 Diabetes Mellitus
}

\author{
Safa Raad Ghareeb $(\mathrm{MBChB})^{1}$, Jalil Ibrahim Alezzi $(\mathrm{PhD})^{2}$, Aseel Jasim \\ $\operatorname{Mohammed}(\mathrm{PhD})^{3}$ \\ ${ }^{1}$ College of Medicine, Alnahreen University,Baghdad, Iraq \\ ${ }^{2}$ College of Medicine, University of Diyala, Diyala, Iraq \\ ${ }^{3}$ College of Medicine, University of Diyala, Diyala, Iraq \\ Correspondence Address: \\ Dr. Safa Raad Ghareeb \\ College of Medicine, Alnahreen University,Baghdad, Iraq \\ email: Safamoh260@gmail.com mobile :009647719406598
}

Received: 10 September 2020

Revised: 15 December 2020

Accepted: 30 September 2020

Published: 15 April 2021

Diyala Medical Journal 2021:20(1): 34- 42

\section{Abstract}

Background: Type 1diabetes (T1D) is immune-mediated disease that presented as a consequence of the gradual destruction of the insulin- producing beta cells, which in results total beta-cell loss and complete dependence on exogenous insulin.

Objective: To explore the potential environmental risk factors associated with the development of T1D among children.

Patients and Methods: This case-control study was conducted in the pediatric department of Albatool teaching hospital in Diyala province, Iraq. A hundred children diagnosed with diabetes mellitus type1 (cases) and hundred children (controls) without diabetes during the period between February 2020 to May 2020. Data collection was done through interviewing parents' or the caregivers of children directly using a questionnaire that was used before for study T1D. the target population was the children attending the outpatient clinic of the endocrine pediatric department of Albatool teaching hospital. A total of 200 children were included in the study. Computer software SPSS (Version 25) and Microsoft Excel (2016) were used to carry out the statistical analysis of data.

Results: The results show Children who had insufficient family income had the highest risk for developing T1D $(\mathrm{p}<0.001)$, and children born to low educated parents, especially illiterate parents, had a risk to develop T1D ( $\mathrm{p}<0.001)$, followed by children whose parent had a history of consanguinity had a high risk for developing T1D ( $\mathrm{p}=0.004)$. Children born to older mothers had a higher risk for developing T1D $(\mathrm{p}=0.04)$. Children with cesarean section delivery had more risk to develop T1D ( $\mathrm{p}<0.000$ ), followed by children a history of early onset of weaning 
had more risk to develop T1D $(\mathrm{p}=0.001)$. Children had a history of bottle feeding had more risk to develop T1D $(\mathrm{p}=0.004)$.

Conclusion: The following factors were associated with significant risk for developing type $1 \mathrm{DM}$ in children: Insufficient family income, low educated parents especially illiterate parents, history of consanguinity. Maternal factors, including older mothers, mothers with a previous history of abortion and infection, and a history of abnormal weight gain. Child factors include, including a history of hospital delivery, a low birth weight, an early onset of weaning, and bottle-feeding.

Keywords: Diabetes Mellitus; children; Diyala

\section{Introduction}

Type 1 diabetes (T1D) is immunemediated disease that develops as a consequence of the gradual destruction of the insulin-producing beta cells, which eventually results in total beta-cell loss and complete dependence on exogenous insulin. $[1,2]$. The cause of T1D remains unknown. There is clear evidence of a genetic predisposition and strong, but circumstantial, evidence for environmental factors triggering autoimmune destruction of the beta cells leading to absolute dependence on insulin treatment [3]. The incidence of T1D is rising. Across Europe, the average annual increase in the incidence in children under 15 years is $3.4 \%$ with the steepest rise in those under 5 years old [4]. T1D is likely the result of environmental changes. This is confirmed by recent experiments showing that the increase in type 1 diabetes has been accompanied by a concomitant widening of the HLA risk profile, which suggests increased environmental pressure on susceptible genotypes. Identification of such environmental factors has proved frustratingly difficult [5]. The most popular candid the effect of a series of parental and prenatal factors on the risk for T1D has been explored in several studies. Although T1D has been associated with parental diabetes and with a much higher risk conveyed from the father $(6.6 \%)$ than from the mother (2.3\%) [6]. Dietary habits can influence the development of T1D. Firstly, the early introduction of cow's milk into the diet of an infant may trigger the disease. Secondly, dietary gluten has been associated with the development of T1D. Finally, nutritional factors, particularly levels of sun exposure and/or vitamin D intake, contribute to T1D inception. Vitamin D may have a protective effect against T1Ddue to its immunosuppressive properties [7].

Breastfeeding seems to provide protection against the risk of developing T1D. Whether this is a direct effect of breast milk or is related to the delayed introduction of cow's milk is unclear. Many new patients with T1D have IgG antibodies to bovine serum albumin, a protein in cow's milk with similarities to the islet cell antigen [8]. Cesarean section was a crude risk factor for diabetes [9]. Finally, psychological stress, through $\beta$-cell stress or direct influence on the immune system, may decrease insulin sensitivity and increase insulin resistance, so contributing to the progression of diabetesrelated autoimmunity [10]. 


\section{Patients and Methods}

The study design: The current study is a case-control study with analytical elements. The target population is the children attending the outpatient clinic of the endocrine Pediatric Department of Albatool Teaching Hospital. A total of 200 children are included in the study from February 2020 to May 2020. The study includes 200 children, 100 children diagnosed with T1D (cases) attending the outpatient's clinic of the pediatric endocrine for follow up and 100 children (controls) who were randomly selected from Pediatric outpatient clinic at the Albatool Hospital without diabetes during the same period.

Data collection is done in endocrine pediatrics outpatients' clinic through interview parents' or the caregiver of the children directly using a special questionnaire that is used before for study T1D. Informed consent is taken by parents/caregivers to participate in the study and they were informed that their identity will not be revealed and the work is done for the purposeful research. The questions are in an Arabic language as well as the an english copy. In order to minimize any embarrassment to the children, parents or guardians are accessed directly to obtain the information. The questionnaire consisted of two parts: The first part includes;

a. socio-demographic

b. maternal factors

c. natal and neonatal factors.

d. feeding history

e. history of exposure to infectious diseases, allergic

f. diet habits

i. serious life event.
The second part is designed to enquire about the presence of T1D and its relevant characteristics.

\section{Statistical analysis}

Computer software SPSS (Version 25) and Microsoft Excel (2016) were used to carry out the statistical analysis of data. Data is analyzed by means of descriptive statistics, percentages, means, and standard deviations. Graphically the data are presented by using pie diagrams. Logistic regression models were applied to estimate the odds ratio (OR) and regression coefficients (B) for the association between the T1D with the underlying risk factors. Data are subjected to multivariate analysis using a logistic regression model with children with T1D (cases) as the dependent variable and the possible risk factors as the independent variables. Level of significance is at the $95 \%$ confidence interval and p- value less than 0.05 .

\section{Results}

This case-control study was conducted in the pediatric department in Albatool teaching hospital from February 2020 to May 2020. The study included 200 children, 100 children diagnosed as diabetes mellitus type 1 (cases) and 100 children (controls) without diabetes during the same period. $50(50 \%)$ patients were males and 50(50\%) patients were females with $\mathrm{M}$ : $\mathrm{F}$ ratio of 1 . The mean age of the total children was $10.1 \pm 3.13$ years (range: 6-16years). There were 64(64\%) patients (cases) aged $\leq 10$ years and 36(36\%) patients aged $>10$ years, their mean age at diagnosis were $5.22 \pm 2.51$ years (range: $2-11$ years). Regarding controls, 50(50\%) child was male and 50(50\%) child were female 
with an $\mathrm{M}: \mathrm{F}$ ratio of 1 , their mean age was $10.2 \pm 3.25$ years (range: 6-19), 63(63\%) patients aged $\leq 10$ years and $37(37 \%)$ patients aged $>10$ years. Of the total patients (cases) 68(68\%) were from rural areas, while $69(69 \%)$ controls had a residence in urban. Family income of cases insufficient in $70(70 \%)$ children, while $24(24 \%)$ controls had insufficient family income. Logistic

Table (1): Logistic regression analysis to determine the significant predictive socioeconomic factors for children with type 1DM

\begin{tabular}{|l||c|c||c||c||}
\hline \multicolumn{1}{|c|}{ Variables } & $\mathrm{B}^{*}$ & P-value & Odds ratio & Confidence intervals \\
\hline \hline Age & -.046 & .371 & .955 & $.864-1.056$ \\
\hline \hline Gender (1) & -.268 & .414 & .765 & $.402-1.455$ \\
\hline \hline Residence (1) & -.682 & .082 & .506 & $.235-1.090$ \\
\hline \hline family income (1) & -1.656 & .000 & .191 & $.089-.410$ \\
\hline \hline B*: Regression coefficient
\end{tabular}

\section{Parental factors}

Table (2) shows logistic regression analysis, children born to low educated parents especially illiterate parents, had a higher risk for developing T1D ( $p<0.001)$,

Table (2): Logistic regression analysis to determine the significant predictive paternal factors for children with type 1DM

\begin{tabular}{|c|c|c|c|c|}
\hline Variables & $\mathrm{B}^{*}$ & P-value & Odds ratio & Confidence intervals \\
\hline Paternal history of DM & 2.215 & .998 & 6.500 & 0 \\
\hline Consanguinity & 1.393 & .004 & 4.027 & $1.520-10.256$ \\
\hline Education & .101 & .034 & 1.107 & 1.292 \\
\hline Education(1) & 1.446 & .000 & 1714.049 & $100.638-29193.316$ \\
\hline Education(2) & 1.055 & 2.000 & 194.655 & $24.597-1540.475$ \\
\hline Education(3) & (.865 & 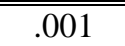 & 18.205 & 3.344-99.100 \\
\hline Education(4) & .752 & .042 & 4.619 & $1.058-20.166$ \\
\hline History of smoking(1) & -.445 & .3 & .641 & $.245-1.679$ \\
\hline
\end{tabular}

\section{Maternal factors}

Table (3) show logistic regression analysis, Children born to older mothers had a higher risk for developing T1D ( $\mathrm{p}=0.04)$, children born to mothers had a history of previous abortion, had more risk to develop T1D ( $\mathrm{p}$ $=0.005$ ), followed by children whose mothershad a history of infection, had a risk followed by children who had a history of consanguinity had high risk 4 times for developing T1D ( $\mathrm{p}=0.004)$. History of DM and smoking had no risk for developing T1D. regression analysis to determine the significant predictive factors for children with type 1DM: Socioeconomic factors: Table (1) shows logistic regression analysis, children who had insufficient family income had the highest risk for developing T1D $(\mathrm{p}<0.001)$. The age and sex of children made no risk for developing T1D. 
Table (3): Logistic regression analysis to determine the significant predictive maternal factors for children with T1D

\begin{tabular}{|c|c|c|c|c|c|}
\hline Variables & $\mathrm{B}^{*}$ & P-value & Odds ratio & \multicolumn{2}{|c|}{$\begin{array}{c}\text { Confidence } \\
\text { intervals }\end{array}$} \\
\hline $\begin{array}{l}\text { Age of mother at delivery of } \\
\text { index child }\end{array}$ & 0.98 & $\overline{.04}$ & 1.103 & \multicolumn{2}{|c|}{$1.001-1.216$} \\
\hline Occupation (1) & .452 & .358 & 1.571 & \multicolumn{2}{|c|}{$24.597-.437$} \\
\hline בautoimmune disease & $\begin{array}{c}-20.646 \\
\end{array}$ & 1.000 & 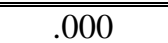 & \multicolumn{2}{|c|}{ 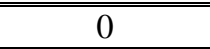 } \\
\hline Infection & 1.179 & 2.005 & 8.308 & .135 & 8.702 \\
\hline antepartum hemorrhage & 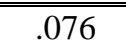 & 2.918 & 1.079 & .251 & 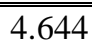 \\
\hline previous abortion & 1.172 & .002 & 4.310 & .146 & 4.656 \\
\hline previous fetal death & 2.615 & .334 & 1.850 & 2.531 & (6.443 \\
\hline abnormal wt. gain & 3.216 & .003 & 5.040 & .005 & 5.327 \\
\hline $\begin{array}{l}\text { drugs intake } \\
\text { (anti_HTN, antibiotics, others) }\end{array}$ & -.156 & .775 & .855 & . .293 & 2.494 \\
\hline
\end{tabular}

\section{Natal and neonatal factors}

Table (4) shows logistic regression analysis, children born in the hospital had more risk to develop T1D ( $p<0.000)$, followed by children who delivered with low birth weight, had a risk for developing T1D $(\mathrm{p}=0.031)$. Duration of pregnancy, history of neonatal jaundice or RDS, infection, use of antibiotics, and vaccination history had no risk to children for developing T1D.

Table (4): Logistic regression analysis to determine the significant predictive natal and neonatal factors for children with T1D

\begin{tabular}{|l||c||c|c|cc|}
\hline \multicolumn{1}{|c||}{ Variables } & $\mathrm{B}^{*}$ & P-value & Odds ratio & \multicolumn{2}{c|}{$\begin{array}{c}\text { Confidence } \\
\text { intervals }\end{array}$} \\
\hline \hline duration of pregnancy & 35.260 & .998 & 2.000 & 0 \\
\hline \hline place of delivery & 3.622 & .000 & 37.415 & 10.058139 .174 \\
\hline \hline Birth weight & 1.693 & .031 & 4.184 & .039 & .858 \\
\hline \hline Neonatal jaundice & -1.239 & .062 & .290 & .079 & 1.063 \\
\hline \hline Respiratory distress syndrome & -16.847 & .999 & .000 & 0 \\
\hline \hline Infection & -16.564 & .999 & .000 & 0 \\
\hline \hline use of antibiotics & 17.670 & .999 & 47203773.610 & .327 \\
\hline Vaccination schedule & .245 & .724 & 1.278 & 4.993 \\
\hline
\end{tabular}

\section{Feeding history}

Table (5) shows logistic regression analysis, children with a history of early onset of weaning had more risk to develop T1D ( $p=0.001)$, followed by children who had a history of bottle feeding had more risk to develop T1D ( $\mathrm{p}=0.004)$. Consumption of cow milk or vitamin $\mathrm{D}$ in the first year of life had no risk to children for developing T1D. 
Table (5): Logistic regression analysis to determine the significant predictive Feeding history of the children with T1D

\begin{tabular}{|c|c|c|c|c|}
\hline Variables & $\mathrm{B}^{*}$ & P-value & Odds ratio & Confidence intervals \\
\hline $\begin{array}{l}\text { feeding pattern in 1st year of } \\
\operatorname{life}(2)\end{array}$ & 7.147 & .004 & 3.64 & 3.953 \\
\hline $\begin{array}{l}\text { duration of exclusive breast } \\
\text { feeding (months) }\end{array}$ & -1.760 & .000 & 6.172 & 6.069 \\
\hline cow milk in 1st year & .104 & .929 & 1.110 & 10.956 \\
\hline onset of weaning & -4.084 & .001 & .017 & .001 \\
\hline Lack of Vit. D in 1st year & 2.201 & .060 & 9.034 & $.914-89.330$ \\
\hline
\end{tabular}

\section{Child previous exposure to some disease}

Table (6) shows logistic regression analysis, children who had a history of exposure to infectious disease, autoimmune

disease, allergic diseases (rhinitis, eczema, asthma, or allergy) had no risk to develop T1D.

Table (6): Logistic regression analysis to determine the significant predictive previous exposure to diseases for children with T1D

\begin{tabular}{|c|c|c|c|c|}
\hline Variables & $\overline{\mathrm{B}^{*}}$ & P-value & Odds ratio & Confidence intervals \\
\hline infectious dis. & -.513 & .181 & .598 & 1.270 \\
\hline autoimmune dis. & -21.408 & .998 & .000 & $\overline{0}$ \\
\hline Allergic diseases (1) & 1116 & $\overline{c .746}$ & 0.890 & 1.799 \\
\hline
\end{tabular}

\section{History of diet and other factors:}

Table (7) shows logistic regression consumed a lot of sweat, or vegetable and analysis, the following not considered as a risk to develop type $1 \mathrm{DM}$ : children who children who had or not physical activity and children who exposed to any type of trauma.

Table (7): Logistic regression analysis to determine the significant predictive History of diet and other factors for children with T1D

\begin{tabular}{|l||c||c|c||}
\hline \multicolumn{1}{|c|}{ Variables } & B $^{*}$ & P-value & Odds ratio \\
\hline \hline freq. intake of sweet & -50.558 & .995 & .000 \\
\hline \hline Frequent intake of vegetables & 34.606 & .996 & 1.000 \\
\hline \hline physical activity & 17.115 & .998 & 2.860 \\
\hline \hline Type & 34.950 & .996 & 1.000 \\
\hline B*: Regression coefficient
\end{tabular}

\section{Discussion}

This Diabetes mellitus is not a single entity but rather a heterogeneous group of disorders in which there are a distinct genetic pattern, as well as other etiological and pathophysiological mechanisms that lead to impairment of glucose tolerance [11]. The current study noticed that there was no significant gender predominance, and the age of children made no risk for developing T1D. The present study found that residence didn't play role in the development of T1D, this result is inconsistent with Awadalla study [12] who founds a positive association between rural residence and higher risk of T1D in the final multivariable analysis model. In the present study, parent's history 
of DM had no risk for developing T1D in their children, while Boljat's study [13] found that diabetic children had a positive family history of type1DM $(p=0.002)$. The current study demonstrated that parent's history of DM cannot be considered as a risk factor for developing T1D, in contrast to the Awadalla study [12] which reported that T1D is significantly associated with a positive family history of T1D Similar to the Ahadi study [14] study, the present study reported that children born to older mothers had a higher risk for developing type 1 DM $(p=0.04)$. While Boljat's study [13] found that maternal age less than 25 years at delivery was associated with a higher risk of T1D ( $\mathrm{p}=0.01)$. The current study found that children born to mothers had a history of previous abortion, had more risk to develop T1D ( $p=0.005)$. Children whose mothers had a history of abnormal weight gain during pregnancy, had a risk for developing T1D $(p=0.003)$. This finding does not agree with Magnus study [15] who reported that maternal pre-pregnancy obesity was associated with childhood-onset T1D, but maternal total gestational weight gain was not associated with type 1 diabetes in their children. Children who delivered by cesarean section, had a higher risk for developing T1D this result was supported by the Awadalla study [12] and the Ahadi study [14] who found that birth through the cesarean section was significantly observed as a predictor positively associated with T1D. Children who delivered with low birth weight, had a risk for developing type $1 \mathrm{DM}(\mathrm{p}=0.031)$, while [16] found that there was no significant association between birth weight and T1D. History of infectious disease showed no risk for children to developing T1D, similarly [13] found that history of infectious diseases was inversely associated with the risk of T1D $(\mathrm{p}=0.03)$. Similar to Stene's study [16] , present study found that there was no significant association between duration of pregnancy and T1D. The current study reveals that vaccination history had no risk to children for developing T1D, similarly to DeStefano's study [17] revealed the same results. Similar to the present study, previous the Awadalla studies [12] reported that positive history of RDS or infection had no risk to children for developing T1D. History of neonatal jaundice had no risk to children for developing type 1 DM, while Awadalla study [12] reported a positive history of neonatal jaundice was a significant risk factor for having T1D . Children who had a history of early onset of weaning were more vulnerable to develop T1D, in contrast to the Awadalla study [12]. Bottle feeding is considered a risk factor for developing type 1 DM $(p=0.004)$, similarly to Awadalla's study [12] and Lund-Blix's studies [18] found that the absence of breastfeeding was a major risk factor for the development of T1D. Lack of vitamin D consumption in the first year of life cannot be considered as a significant protective factor for type1DM, in contrast to Ahadi M study [14] who reported that the lack of vitamin D supplementation was significantly associated with T1D. Exposure to any type of trauma not associated with a risk for developing T1D, in contrast with results of Boljat A study [13] who found that stressful life events during childhood $(\mathrm{p}=0.02)$ significantly associated with a risk of T1D. 


\section{Conclusions}

The following factors were associated with significant risk for developing type $1 \mathrm{DM}$ in children: Insufficient family income, low educated parents especially illiterate parents, history of consanguinity. Maternal factors, including older mothers, mothers with a history of previous abortion and infection, history of abnormal weight gain. Child factors, including ahistory of hospital delivery,a low birth weight, an early onset of weaning, and bottle-feeding.

\section{Recommendations}

Special action needs to be taken to develop a public health strategy to educate the population and increase their awareness about possible risk factors and complications of diabetes in children. Establishing a health education unit in each diabetic center, the duty of which is to stress the role of regular visits to the center for the proper control of the disease and preventing its complication. Development of school health educational program, to instruct the educational staff about notifying the possible risk factors. Further large population, community-based, prospective studies are recommended in order to determine the scope of this problem nationwide and to assess predictors for developing type $1 \mathrm{DM}$.

Source of funding: The author did not receive financial support for this research and publication of this article.

Ethical clearance: This study was granted ethical approval from the Ethical Committee of the Collage of Medicine at Diyala medical University.
Conflict of interest: The author declares that there is no conflict of interest regarding the publication of this article.

\section{References}

[1]Mansour A.A, Al-Maliky A, Kasem B, Determinants of loss of glycemic control in patients with type 1 diabetes mellitus. Prospective cohort study from Iraq; Journal of Diabetes Research \& Clinical Metabolism; 2005 doi: 10.7243/2050-0866-2-21.

[2]Atkinson M.A, The Pathogenesis and Natural History of Type 1 Diabetes; Cold Spring Harb Perspect Med; 2012, doi: 10.1101/cshperspect. a007641.

[3]Patterson Ch , Guariguata L, Dahlquist G, Solte'sz G, Ogle G, Silink M, Diabetes in the young - a global view and worldwide estimates of numbers of children with type 1 diabetes, Diabetes Research and Clinical Practice; 2013, doi.org/10.1016/j.diabres.2013.11.005.

[4]Ozougwu J , Obimba, K. C., Belonwu, C. D , and Unakalamba C.D,The pathogenesis and pathophysiology of type 1 and type 2 diabetes mellitus, Journal of Physiology and Pathophysiology; 2013, 4(4), 46-57, DOI 10.5897/JPAP2013.0001 .

[5]Gillespie K.M, Type 1 diabetes: pathogenesis and prevention, CMAJ.; 2006,18; 175(2): 165-170, doi: 10.1503/cmaj.060244.

[6]Hussen H.I, Persson M, Moradi T, Maternal overweight and obesity are associated with increased risk of type 1 diabetes in offspring of parents without diabetes regardless of ethnicity, Diabetologia; 2015, 58, pages 1464-1473.

[7]Aggarwal I, the Epidemiology, Pathogenesis, and Treatment of Type 1 
Diabetes Mellitus, INQUIRIES JOURNAL; 2015, 7, 11, 1/2.

[8]Joseph ER, Malcolm DCD, John WG, et al . Practical Endocrinology and Diabetes in Children. 3rd Edition ed: Blackwell Publishing Ltd; 2011(chapter 1).

[9]Penders J, Thijs C, Vink C, Stelma FF, Snijders B, Kummeling I, et al. Factors influencing the composition of the intestinal microbiota in early infancy. Pediatrics. 2006; 118:511-521.

[10]Sepa A, Ludvigsson J. Psychological stress and the risk of diabetes-related autoimmunity: a review article. Neuroimmunomodulation. (2006) 13:301-8. doi: $10.1159 / 0001048$.

[11] AL-Rubaee R.J, Newly diagnosed type 1 Diabetes Mellitus in Dhi-qar city(IRAQ) sociodemographic study, IOSR Journal of Dental and Medical Sciences (IOSR-JDMS); 2013, 10, 2, PP 53-62.

[12]Awadalla N. J, Hegazy A. A, Abd ElSalam M, Elhady M, Environmental Factors Associated with Type 1Diabetes Development: A Case Control Study in Egypt, Int. J. Environ. Res. Public Health; 2017, 14, 615, doi:10.3390/ijerph14060615. [13] 13- Boljat A , Gunjača I, Konstantinović I, Vidan N, Perica V. B, Pehlić $\mathrm{M}$, Škrabić $\mathrm{V}$, Zemunik $\mathrm{T}$, Environmental Risk Factors for Type 1 Diabetes Mellitus Development, Exp Clin Endocrinol Diabetes; 2017, 125(8):563-570. doi: 10.1055/s-0043-109000. Epub $2017 \mathrm{Jul}$ 27.

[14]Ahadi M , Tabatabaeiyan M, Moazzami $\mathrm{K}$, Association between environmental factors and risk of type 1 diabetes - a casecontrol study, Endokrynol Pol; 2011;62(2):134-7.
[15]Magnus M.C, Olsen S.F, Granstrom Ch, Lund-Blix N. A, Svensson J, Johannesen J, Paternal and maternal obesity but not gestational weight gain is associated with type 1 diabetes, Int J Epidemiol. ; 2018, 1;47(2):417-426. doi: 10.1093/ije/dyx266

[16]Stene L. C, P Magnus, R T Lie, O Søvik, $G$ Joner, Birth weight and childhood onset type 1 diabetes: population based cohort study, BMJ; 2001 Apr 14;322(7291):889-92. doi: 10.1136/bmj.322.7291.889.

[17]DeStefano F, Mullooly J. P, Okoro C. A, Chen R.T, S. Marcy M, Ward J. I, Childhood Vaccinations, Vaccination Timing, and Risk of Type 1Diabetes Mellitus, Pediatrics 2001;108, $\quad 112, \quad$ DOI: 10.1542/peds.108.6.e112.

[18]Blix N. A, Sander S. D, Størdal K, Andersen A. N, Rønningen K. S, Joner G, Infant Feeding and Risk of Type 1 Diabetes in Two Large Scandinavian Birth Cohorts, Diabetes Care. ; 2017, 40(7):920-927. doi: 10.2337/dc17-0016. Epub 2017,9. 